\title{
CONTRIBUIÇÃO À ANATOMIA ARTERIAL DO CÓLON SIGMÓIDE APLICÁVEL A OPERAÇÕES DE ABAIXAMENTO
}

\author{
Sávio Lana SIQUEIRA ${ }^{1}$ e Alcino LÁZARO-da-SILVA ${ }^{2}$
}

RESUMO - Racional - A vascularização do sigmóide apresenta variações que podem ser importantes no uso daquele segmento nas operações de intestino grosso. Objetivos - Realizou-se investigação anatômica da vascularização arterial do colón sigmóide para se obter um parâmetro que possa ser aplicado a raciocínio tático nas operações de abaixamento do cólon sigmóide ao períneo, após a ressecção alargada do reto-ânus e seus esfíncteres na neoplasia maligna retoanal. Material e Métodos - Analisou-se o mesocólon sigmóide de 33 cadáveres formolizados, 22 do sexo masculino e 11 do feminino, através de dissecções destes com os intestinos in situ. Para isso, cateterizou-se a artéria mesentérica inferior, sendo esta contrastada com solução de aguarrás, thinner, látex de cor vermelha e policloreto de vinil. Resultados - A artéria mesentérica inferior originou-se, na maioria dos casos, na face anterior esquerda da aorta abdominal, a uma distância média de 4,3 cm do seu ângulo inferior de bifurcação; a artéria cólica esquerda, em 25 cadáveres, originou-se diretamente da artéria mesentérica inferior. O número de artérias sigmóideas variou de um a cinco. Verificou-se um plano arterial principal que iniciaria na ligadura da artéria mesentérica inferior, abaixo da origem da artéria cólica esquerda, sendo o sigmóide abaixado ao períneo. Conclusão - O conhecimento da vascularização do colón sigmóide e sua observação no transoperatório poderiam orientar a tática e técnica cirúrgica na operação de abaixamento cólico ao períneo e colostomia perineal.

DESCRITORES - Cólon sigmóide, anatomia \& histologia. Artéria mesentérica inferior. Colostomia.

\section{INTRODUÇÃO}

A vascularização do sigmóide apresenta variações que podem ser importantes no uso daquele segmento nas operações de intestino grosso.

$\mathrm{Na}$ presença de tumor primitivo do reto, em que sua ressecção total se faz necessária, existe a preocupação dos cirurgiões de tentar o abaixamento do sigmóide e, assim, preservar o trânsito intestinal fecal.

Quando o tumor atinge o reto-ânus, há necessidade de se fazer a ressecção alargada em que o conjunto de esfíncteres fica englobado. Com isto, o paciente terá uma colostomia abdominal definitiva.

$\mathrm{Na}$ tentativa de se preservar ao máximo o paciente desta condição pouco agradável, há o empenho no sentido de que o abaixamento do cólon esquerdo propicie uma colostomia perineal e alguns autores como HABR-GAMA ${ }^{(9)}$, SCHMIDT ${ }^{(22)}$,
WONG e WEE(28) e SIMONSEN ${ }^{(23)}$ tentaram vários recursos para buscar uma continência mesmo relativa em certos casos.

O sigmóide é muito útil porque apresenta boa extensão e, em certos pacientes, ótima vascularização. Ele precisa ser dissecado e manipulado para se obter o abaixamento bem vascularizado. No paciente magro a visão das arcadas fica mais fácil, no obeso isto não ocorre, mesmo com transiluminação.

Diante disso, na busca de melhor recurso para o uso do cólon sigmóide em operações, desenvolveu-se uma investigação anatômica em que sua vascularização arterial fosse estudada, com análise dos seus modelos vasculares arteriais.

\section{MATERIAL E MÉTODO}

Este estudo foi realizado através da observação e dissecação de 33 cadáveres adultos formolizados, sendo 11 do sexo feminino e 22 do masculino.

Trabalho realizado na Disciplina de Anatomia Humana do Departamento de Morfologia da Faculdade de Ciências Médicas de Minas Gerais e ${ }^{2}$ Departamento de Cirurgia do Aparelho Digestivo da Faculdade de Medicina da Universidade Federal de Minas Gerais, Belo Horizonte, MG. Endereço para correspondência: Dr. Savio Lana Siqueira - Rua Guajajaras, 600/1301 - Lourdes - 30180-100 - Belo Horizonte, MG. 
A via de acesso utilizada à cavidade peritonial foi por laparotomia longitudinal mediana xifopúbica, seguida de laparotomia transversal bilateral, a partir do nível da $11^{\underline{a}}$ costela, da extremidade flanco-lombar esquerda à direita.

$\mathrm{Na}$ cavidade peritonial de todos os cadáveres foi investigada e constatada, macroscopicamente, a ausência de alterações macroscópicas viscerais e vasculares. Identificou-se em um cadáver masculino a presença do rim esquerdo em situação pélvica, o que não prejudicou o estudo de seu mesocólon sigmóide.

A dissecção da região retroperitonial infrapancreática foi iniciada sobre a veia cava inferior, preservando, a princípio, o conteúdo anterior à aorta abdominal.

Iniciou-se, então, a dissecção da aorta abdominal, logo abaixo da emergência da artéria mesentérica superior.

A partir da exposição do óstio interno da origem da artéria mesentérica inferior na aorta, foi introduzido por $0,5 \mathrm{~cm}$ na mesma artéria um cateter de policloreto de vinil (PVC) atóxico, siliconizado, de número 6 , com a ponta seccionada transversalmente e aí fixada por ligadura externa de fio de poliéster trançado, pré-cortado 2-0, tomando-se o cuidado de não obstruir o lúmen do cateter.

O contraste utilizado constou de solução de aguarrás (solventes alifáticos), thinner (etanol, solventes aromáticos, acetatos, ésteres e glicóis), adquirida no comércio num único preparo com nome de "thinner 3.500", na quantidade de $10 \mathrm{~cm}^{3}$, misturados a $5 \mathrm{~cm}^{3}$ de tinta látex vermelha, sendo que a esta última solução adicionaram-se $3 \mathrm{~g}$ de PVC em fragmentos pequenos de plástico, extraídos de folhas do mesmo material.

O preparo foi misturado manualmente, durante 5 minutos, fazendo-se com que ficasse homogêneo e fluido o bastante para preencher os ramos arteriais mais finos da região estudada, procedimento feito em dois cadáveres de cada vez.

O contraste obtido era, então, aspirado para uma seringa descartável de $10 \mathrm{~cm}^{3}$ e injetado manual e lentamente, $7 \mathrm{~cm}^{3}$ do mesmo na artéria mesentérica inferior através da conexão de um cateter de PVC atóxico de número 6 , siliconizado, do tipo uretral, introduzido na mesma artéria pela luz da aorta abdominal e fixado por ligadura de fio de poliéster trançado 2-0, na origem da aorta.

Esta dissecção compreendeu todo o mesocólon sigmóide, a porção inferior da aorta, os vasos ilíacos comuns, externos e internos esquerdos, o ureter e vasos gonadais do mesmo lado e, também, o retroperitônio pélvico à esquerda da coluna vertebral.

A artéria mesentérica inferior foi dissecada juntamente com a artéria retal superior, até o nível da borda superior e anterior do corpo da terceira vértebra sacral, através da face anterior do mesocólon sigmóide e da face lateral direita do início do mesorreto.

Foram dissecados todos os ramos da artéria mesentérica inferior no mesocólon sigmóide, desde o início do sigmóide, incluindo-se número variável de ramos retossigmóideos da transição do cólon sigmóide com o reto. Considerou-se o início do cólon sigmóide aproximadamente no nível da crista ilíaca como relatado por GARDNER et al. ${ }^{(6)}$ e HOLLINSHED e ROSSE(10).

Mensurou-se a distância entre a origem da artéria mesentérica inferior e o ângulo inferior da dicotomia da aorta abdominal em artérias ilíacas comuns. Mediu-se, também, o comprimento da artéria mesentérica inferior, desde sua origem até o início das artérias sigmóideas e o comprimento do ramo sigmóideo mais central, incluindo possíveis ramos secundários, segmentos da arcada marginal e seus ramos retos, até a face mesocólica do sigmóide. Conseguiu-se, assim, uma medida entre a origem da artéria mesentérica inferior e o cólon sigmóide, a mais retilínea e central possível.

\section{RESULTADOS}

Como não foi possível obter dados biométricos, a estatística foi feita com os dados das artérias estudadas.

\section{Artéria mesentérica inferior}

Em todos os 33 cadáveres estudados, a artéria mesentérica inferior estava presente, tipicamente, vascularizando o cólon esquerdo e o reto superior. Em nenhum dos casos estava obstruída por coágulos.

A artéria mesentérica inferior de todos os cadáveres dissecados emergia, predominantemente, da face anterior esquerda da aorta abdominal, sempre abaixo da origem das artérias gonadais, porém a uma distância variável do ângulo inferior da bifurcação da aorta abdominal em artérias ilíacas comuns. Esta distância variou de 3,2 cm a $6,4 \mathrm{~cm}$ (Tabela 1$)$.

TABELA 1 - Comparação da medida da distância entre a origem da artéria mesentérica inferior e o ângulo inferior da bifurcação da aorta abdominal em relação aos sexos e total

\begin{tabular}{lcccccc}
\hline & \multicolumn{5}{c}{ Medidas descritivas (cm) } & \\
\cline { 2 - 5 } Sexo & $\mathbf{n}$ & Mínimo & Máximo & Média & DP & $P$ \\
\hline Masculino & 22 & 3,5 & 5,8 & 4,3 & 0,7 & \\
Feminino & 11 & 3,2 & 6,4 & 4,2 & 0,9 & \\
Total & 33 & 3,2 & 6,4 & 4,3 & 0,8 & \\
\hline
\end{tabular}

$\mathrm{O}$ valor de $P$ refere-se ao teste $t$ de Student para amostras independentes 


\section{Artéria cólica esquerda}

A artéria cólica esquerda estava presente nos 33 cadáveres dissecados, em que era responsável pela irrigação de todo o cólon descendente e da transição deste com o sigmóide. A artéria cólica esquerda originava-se sob duas formas: diretamente da artéria mesentérica inferior ou de um ramo comum com um ramo de artérias sigmóideas ou com uma artéria sigmóidea (Tabela 2).

TABELA 2 - Distribuição da origem da artéria cólica esquerda em relação ao sexo

\begin{tabular}{lccccc}
\hline & \multicolumn{5}{c}{ Origem } \\
\cline { 2 - 5 } Sexo & \multicolumn{2}{c}{ Direta } & \multicolumn{2}{c}{ Indireta } & \\
\cline { 2 - 5 } & $\mathbf{n}$ & $\%$ & $\mathbf{n}$ & $\mathbf{\%}$ & Total \\
\hline Masculino & 16 & 69,6 & 6 & 60,0 & 22 \\
Feminino & 7 & 30,4 & 4 & 20,0 & 11 \\
Total & 23 & 100,0 & 10 & 100,0 & 33 \\
\hline
\end{tabular}

$P=0,6960$ (teste exato de Fisher)

O nível de origem da artéria cólica esquerda relacionado com o nível de término do cólon descendente pouco variou neste estudo. Em 29 casos, ou seja, em 87,9\% a artéria cólica esquerda emergiu direta ou indiretamente da aorta abdominal em nível mais baixo que o do término do cólon descendente. Em apenas dois casos essa origem se fez neste nível e também em outros dois, acima do término do descendente.

A delimitação do ângulo inferior da bifurcação da aorta abdominal em artérias ilíacas comuns foi de grande importância, pois a artéria cólica esquerda se originava acima deste ponto em 26 casos (17 do sexo masculino e 9 do feminino).

Após suas origens, as artérias cólicas esquerdas tomavam uma direção para a esquerda, estando incluídas próximo à lateral esquerda da raiz superior dos mesocólons sigmóides, junto aos seus vértices. Deste ponto em diante, as artérias cólicas esquerdas estudadas apresentaram curto trajeto no interior dos mesocólons sigmóides, ramificando-se em um ramo ascendente e outro descendente, o que foram constatados em 26 dos 33 cadáveres, ou seja, $78,8 \%$ dos casos. O ramo ascendente tinha seu trajeto para a flexura esquerda do cólon e o descendente tomava uma direção para área de limite entre os cólons descendente e sigmóide, por isso preferiu-se chamá-lo de ramo para a transição descendentesigmóide. Em todos os 33 cadáveres, a artéria cólica esquerda contribuiu para a arcada marginal.
A artéria cólica esquerda de 21 cadáveres originou um ou mais ramos para o cólon sigmóide, sendo que desses 21 casos, 16 originavam um ramo para o sigmóide (10 masculinos e 6 femininos), quatro cadáveres masculinos apresentavam dois ramos, e em um caso, também masculino, emitiam-se três ramos para o cólon sigmóide. Nos outros 12 casos, 5 femininos e 7 masculinos, a artéria cólica esquerda não emitia ramos para o sigmóide.

\section{Artérias sigmóideas}

O número de artérias sigmóideas nos cadáveres dissecados no presente estudo variou de uma a cinco, como mostram respectivamente as Figuras 1, 2, 3, 4, sendo que no sexo feminino este número apresentou-se de um a três ramos sigmóideos. No sexo masculino foram evidenciadas até cinco artérias sigmóideas (Tabela 3).

Observou-se que não houve relação entre o número maior de artérias sigmóideas com maior largura de mesocólons sigmóide.

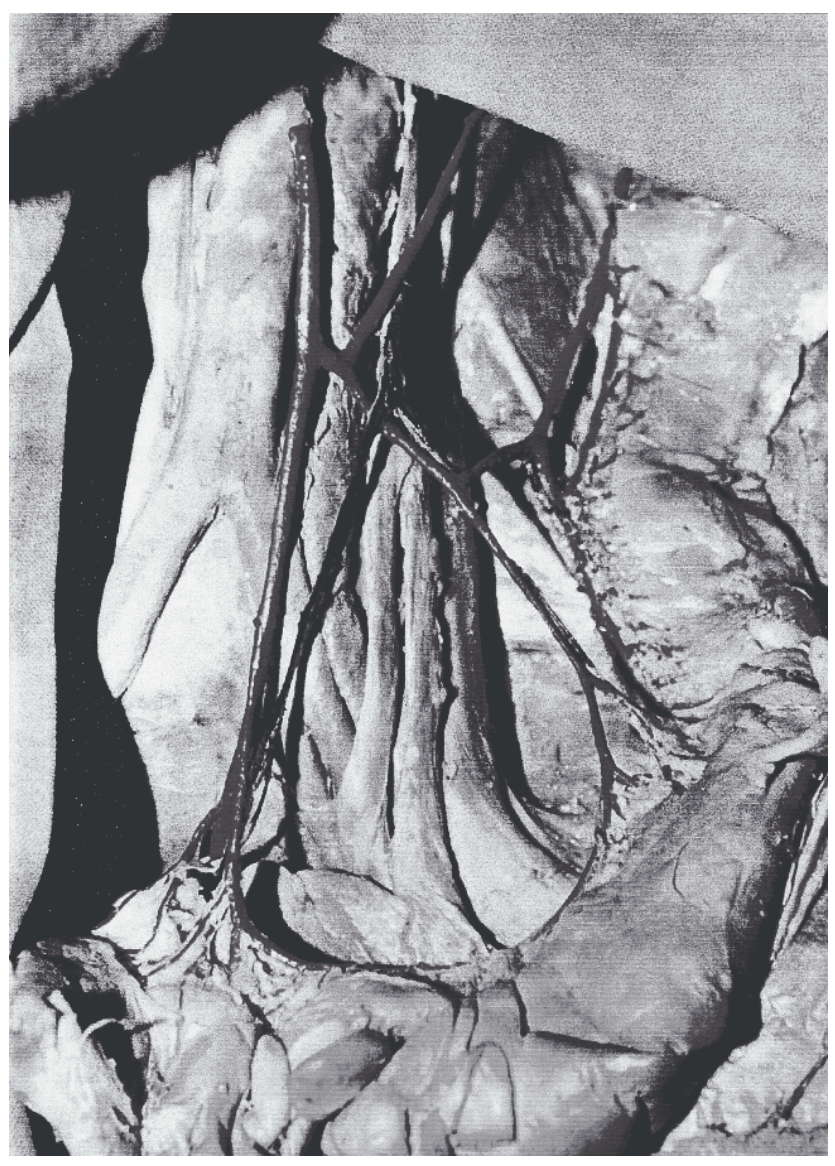

FIGURA 1 - Dissecção no cadáver no 25 


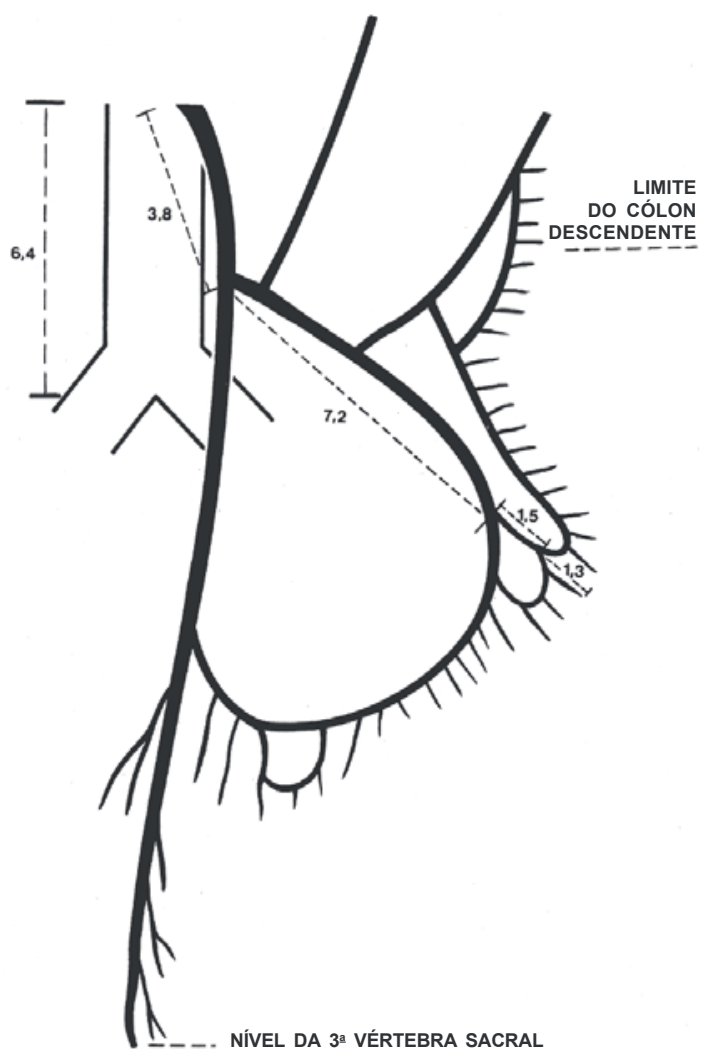

FIGURA 2 -Esquema da dissecção no cadáver no 25

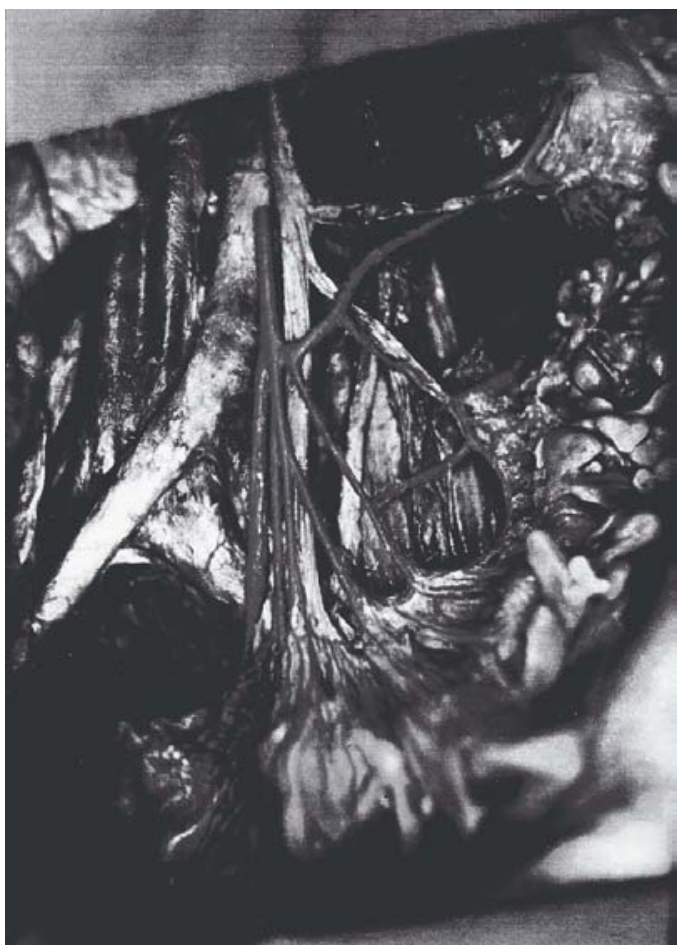

FIGURA 3 - Dissecção no cadáver nº 20. Sexo masculino

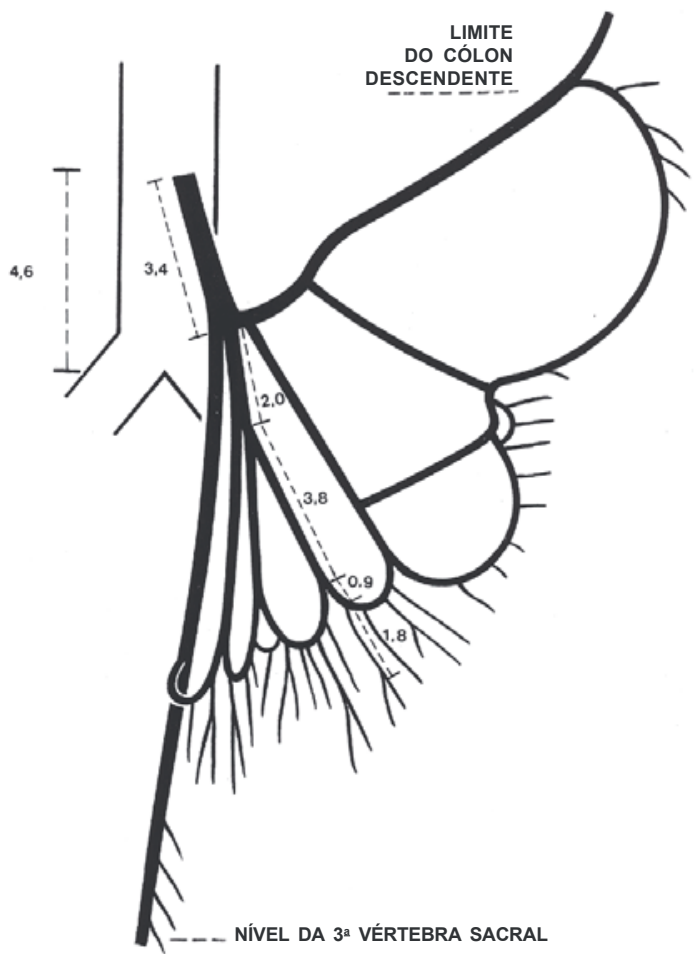

FIGURA 4 - Esquema da dissecção no cadáver no 20

TABELA 3 - Distribuição dos cadáveres em relação ao número de artérias sigmóideas por sexo e no total

\begin{tabular}{|c|c|c|c|c|c|c|}
\hline \multirow[b]{3}{*}{ № artérias } & \multicolumn{4}{|c|}{ Sexo } & & \\
\hline & \multicolumn{2}{|c|}{ Masculino } & \multicolumn{2}{|c|}{ Feminino } & \multicolumn{2}{|c|}{ Geral } \\
\hline & $\mathbf{n}$ & $\%$ & $\mathbf{n}$ & $\%$ & $\mathbf{n}$ & $\%$ \\
\hline Uma & 1 & 4,5 & 1 & 9,1 & 2 & 6,1 \\
\hline Duas & 4 & 18,2 & 4 & 36,4 & 8 & 24,2 \\
\hline Três & 10 & 45,5 & 6 & 54,5 & 16 & 48,5 \\
\hline Quatro & 4 & 18,2 & 0 & 0,0 & 4 & 12,1 \\
\hline Cinco & 3 & 13,6 & 0 & 0,0 & 3 & 9,1 \\
\hline Total & 22 & 100,0 & 11 & 100,0 & 33 & 100,0 \\
\hline
\end{tabular}

Todas as artérias sigmóideas comunicavam-se entre si, exceto no cadáver de número 13 do sexo feminino, no qual a última dessas artérias não se anastomosava com outra sigmóidea que a antecedia, ou seja, uma segunda artéria sigmóidea. A última artéria sigmóidea, em quase todos os casos, comunicava-se com a artéria retal superior, exceto nos cadáveres de números 6, 15, 13 e 16, sendo os dois primeiros do sexo masculino e os dois últimos do sexo feminino, mostrando que esta anastomose não estava presente. 


\section{Modelos arteriais do mesocólon sigmóide}

Seguindo um dos objetivos deste estudo, foi medida a distância da origem da artéria mesentérica inferior à parede do cólon em sua face mesocólica, distância esta obtida sobre o trajeto da mesma artéria e seus ramos sigmóideos e retos mais centrais do mesocólon sigmóide. Esta distância variou de 9,9 cm a 18,6 cm (Tabela 4).

TABELA 4 - Comparação da medida da distância do mesocólon sigmóide entre a origem da artéria mesentérica inferior e a metade do cólon sigmóide em relação aos sexos e no total

\begin{tabular}{lcccccc}
\hline & & \multicolumn{3}{c}{ Medidas descritivas (cm) } & \\
\cline { 3 - 5 } Sexo & $\mathbf{n}$ & Mínimo & Máximo & Média & DP & \multirow{P}{*}{} \\
\hline Masculino & 22 & 10,0 & 18,6 & 14,1 & 2,0 & \\
& & & & & & 0,5432 \\
Feminino & 11 & 9,9 & 17,5 & 14,6 & 2,3 & \\
Total & 33 & 9,9 & 18,6 & 14,3 & 2,1 & \\
\hline
\end{tabular}

O valor de $P$ refere-se ao teste $t$ de Student para amostras independentes

Pelo mesmo método e princípio, foi determinada a medida em todos os cadáveres, da distância entre a arcada marginal e o ponto de implantação do mesocólon sigmóide no cólon. Esta distância variou de $0,8 \mathrm{~cm}$ a $3,5 \mathrm{~cm}$ nos cadáveres femininos, de números 21 e 7 , e de $0,8 \mathrm{~cm}$ a $3,6 \mathrm{~cm}$ nos do sexo masculino, de números 17 e 24, verificando-se também que quatro cadáveres apresentavam esta distância em 2,5 cm, os de números 11, 26, 27 e 29, quatro outros com esta mensuração igual a $2 \mathrm{~cm}$, os cadáveres de números 10,14 , 22 e 33 (Tabela 5)

TABELA 5 - Comparação da medida da distância da arcada marginal ao cólon sigmóide, mensurada em $\mathrm{cm}$ no nível da metade do mesocólon sigmóide em relação aos sexos e no total

\begin{tabular}{lcccccc}
\hline & & \multicolumn{4}{c}{ Medidas descritivas (cm) } & \\
\cline { 3 - 5 } Sexo & n & Mínimo & Máximo & Média & DP & $P$ \\
\hline Masculino & 22 & 0,8 & 3,6 & 2,0 & 0,7 & \\
& & & & & & 0,1733 \\
Feminino & 11 & 0,8 & 3,5 & 1,6 & 0,8 & \\
Total & 33 & 0,8 & 3,6 & 1,9 & 0,7 & \\
\hline
\end{tabular}

$\mathrm{O}$ valor de $P$ refere-se ao teste $t$ de Student para amostras independentes

\section{DISCUSSÃO}

GRIFFITHS $^{(8)}$ observou que os vasos cólicos deveriam ser estudados com a víscera in situ. A retirada da peça de sua localização poderia trazer informações equivocadas.

WAINSTEIN ${ }^{(27)}$ relatou que a artéria cólica esquerda, por ele chamada de superior, originava-se da artéria mesentérica inferior, ou mesmo de um ramo comum com as artérias sigmóideas. Sua observação concorda com as de CORSY e AUBERT ${ }^{(1)}$, CUNÉO$^{(2)}$ e HOVELACQUE ${ }^{(11)}$.

MICHELS et al. ${ }^{(16)}$, NAHAS ${ }^{(19)}$ e ESPER $^{(5)}$ relataram que a artéria mesentérica inferior dividia-se em um ramo ascendente e outro descendente, tendo trajeto ascendente e não horizontal.

VanDAMME $^{(25)}$ e ROSENBLUM et al. ${ }^{(21)}$ relataram que a artéria cólica esquerda ou ramo ascendente da artéria mesentérica inferior, alcançava o ângulo esplênico.

GOLIGHER $^{(7)}$, MICHELS et al. ${ }^{(16)}$ e HOLLINSHEAD e ROSSE ${ }^{(10)}$ relataram número variável de uma a cinco artérias sigmóideas.

$\mathrm{DEGNI}^{(3)}$ relatou que as artérias sigmóideas apresentavam três formas de origem. No primeiro grupo, as artérias sigmóideas originavam-se da mesentérica inferior, de forma isolada $(6,7 \%)$, por um ramo comum $(9,7 \%)$ ou por um ramo comum e isolado $(17,3 \%)$. No segundo grupo, essas artérias emergiam das artérias mesentérica inferior e cólica esquerda, isoladamente, em 40,4\% desta última e por um ramo comum da artéria mesentérica inferior e, vice-versa, em $23 \%$. As artérias sigmóideas do terceiro grupo originavam-se da artéria cólica esquerda em $2,8 \%$ dos casos.

Vários autores, ao longo de anos, vêm definindo e demonstrando arcadas arteriais anastomóticas paralelas ao trajeto dos cólons. Muitas interpretações foram dadas a essas arcadas.

RIOLAN $^{(20)}$ descreveu a arcada arterial no mesocólon transverso, que anastomosava o território da artéria mesentérica superior com o da artéria mesentérica inferior. Porém, von HALLER ${ }^{(26)}$ foi o primeiro a descrever que ramos da artéria mesentérica superior anastomosavam-se com os da artéria mesentérica inferior, próximos da parede colônica. Esta foi a primeira descrição da arcada marginal.

DRUMMOND $^{(4)}$ relatou a importância da arcada marginal como suprimento vascular para as resssecções colônicas, sendo o primeiro a usar o termo artéria marginal.

KORNBLITH et al. ${ }^{(13)}$, ROSENBLUM et al. ${ }^{(21)}$ e MOSKOWITZ et al. ${ }^{(18)}$ redefiniram as conexões entre as artérias mesentéricas superior e inferior. A conexão periférica mais próxima e paralela ao intestino grosso seria a arcada marginal. A mais medial, anastomosando as artérias cólicas média e esquerda, foi definida como artéria anastomótica central. Aquela conexão localizada na raiz do mesocólon transverso, unindo a artéria cólica média ao ramo ascendente da cólica esquerda, seria a arcada de Riolan. Os dois últimos autores, apesar de pequena divergência, redefiniram essas vias e mostraram que a 
interpretação das mesmas depende da anatomia funcional e da variação anatômica de cada caso.

O cólon sigmóide é bem vascularizado somente pela anastomose entre os sistemas das artérias mesentéricas superior e inferior, via arcada marginal. Mesmo com a necessidade da ligadura da artéria mesentérica inferior em sua emergência na aorta abdominal, para abaixamento cólico sem tensão dos vasos ou com preservação da mesma e não-angulação dos vasos retos, esta anastomose é de vital importância para o sucesso da operação. Faz-se, porém, necessário traçar um caminho de ligaduras dos ramos da artéria mesentérica inferior, mesmo com ou sem a sua preservação, para efetivo abaixamento da metade proximal do cólon sigmóide ao períneo ou ânus e boa ressecção linfonodal, havendo ou não a mobilização do cólon descendente e parte do transverso. Sendo esta necessária, a artéria mesentérica inferior deveria ser ligada em definitivo, somente após a constatação da continuidade da arcada marginal na parte esquerda dos cólons. O fluxo sangüíneo viria, então, dos ramos cólicos médios da artéria mesentérica superior, ou mesmo através dos cólicos direitos, na ausência destes últimos ${ }^{(15)}$.

Para abaixamento efetivo do cólon sigmóide, os ramos mesocólicos da artéria mesentérica inferior deveriam ser ligados de maneira a abranger maior campo linfonodal com a preservação da metade proximal do sigmóide.

As ligaduras vasculares abrangeriam, de inferior para superior, os vasos retais superiores, os vasos sigmóideos, com preservação dos vasos cólicos esquerdos, na possibilidade de manutenção do fluxo sangüíneo pela artéria mesentérica inferior e também pela arcada marginal. Essas ligaduras, portanto, anatomicamente, não impediriam o fluxo de chegar à extremidade distal do coto sigmóideo proximal. Elas deveriam ser feitas a uma distância correta da face mesocólica do sigmóide, a fim de não lesarem a arcada marginal ${ }^{(15)}$.

Na possibilidade de preservação da artéria mesentérica inferior a dissecação e exérese do mesocólon sigmóide, juntamente com seus linfonodos, iniciar-se-ia logo após a origem do ramo cólico esquerdo, na maioria dos casos no nível da bifurcação da aorta abdominal, a aproximadamente $4 \mathrm{~cm}$ da origem da mesentérica inferior, onde seria procedida a ligadura dos vasos retais superiores. A partir deste ponto, prosseguiria em sentido lateral, em direção ao ramo cólico esquerdo, sempre respeitando o trajeto da arcada marginal que poderia ser constatada por transiluminação ou procedendo-se a ligadura dos vasos sigmóideos a uma distância segura da mesma $\operatorname{arcada}^{(15)}$, que neste estudo variou de $0,8 \mathrm{~cm}$ a $3,6 \mathrm{~cm}$ da face mesocólica do sigmóide. Segundo STEWARD e RANKIN ${ }^{(24)}$ esta distância é inconstante, variando de $1 \mathrm{~cm}$ a $8 \mathrm{~cm}$.

$\mathrm{Na}$ necessidade de ligadura da artéria mesentérica inferior para o abaixamento, nos casos de mesocólon e cólon sigmóide curtos, ou mesmo na suspeita de comprometimento linfonodal da raiz da mesma artéria, todo o mesocólon sigmóide deveria ser retirado em bloco com o reto, preservando-se, porém, ao máximo, a faixa de mesocólon que traz consigo a arcada marginal, com fluxo sangüíneo provindo da artéria mesentérica superior. Algumas vezes, portanto, a mobilização do cólon descendente e parte do transverso far-se-ia necessária ${ }^{(15)}$

Toda a área do mesocólon sigmóide que seria retirada em bloco com o reto, nos casos de preservação da artéria mesentérica inferior, consistiria neste plano arterial acessório de irrigação do cólon sigmóide. Este plano conteria os vasos mesocólicos não essenciais à vitalidade do segmento sigmóideo a ser abaixado, compreendido entre os pontos de ligaduras vasculares, anteriormente assinalados ${ }^{(15)}$.

MILES ${ }^{(17)}$ baseou-se nas vias linfáticas de disseminação da neoplasia maligna do reto e apresentou seus princípios, sendo sua técnica de amputação radical difundida, colocando em plano secundário a questão de preservação dos esfíncteres.

Segundo LÁZARO-da-SILVA ${ }^{(14)}$, a colostomia abdominal definitiva nem sempre é mais aceitável que a neoplasia em si, ou mesmo a sua recidiva.

JAMIESON e DOBSON ${ }^{(12)}$ e DEGNI ${ }^{(3)}$ preconizaram a ligadura da artéria mesentérica inferior, após a origem da artéria cólica esquerda, o que levaria a um ótimo fluxo sangüíneo ao segmento a ser abaixado, não sendo necessário remover os linfonodos da raiz da artéria mesentérica inferior, acima da origem da artéria cólica esquerda por não serem linfonodos primários e, assim, menos afetados pela neoplasia. A ligadura da artéria mesentérica inferior abaixo de cólica esquerda permitiria melhor mobilização do cólon sigmóide.

LÁZARO-da-SILVA ${ }^{(15)}$ relatou que na indicação de ligadura dos vasos mesentéricos inferiores, o cólon descendente e parte do transverso deveriam ser mobilizados, preservando-se, quando possível, a arcada marginal.

Estes três últimos trabalhos, mesmo estudando sobretudo os aspectos anatômicos, fizeram referências a possível aplicação anatômica quando se vai proceder o abaixamento perineal.

No abaixamento, o que se busca é a vitalidade do segmento levado ao períneo, preservando-se ao máximo as arcadas arteriovenosas.

Neste estudo, a conclusão é que se obteria melhor resultado expondo-se a raiz da artéria mesentérica inferior e ligando-a somente após a emergência da artéria cólica esquerda. Logo, o conhecimento da vascularização do cólon sigmóide e a criteriosa observação desta no transoperatório poderiam orientar melhor a tática e a técnica cirúrgica para amputação do reto com abaixamento colônico ao períneo e colostomia perineal. 
Siqueira SL, Lázaro-da-Silva A. Contribution to arterial anatomy of the sigmoid colon useful for colon lowering down techniques. Arq Gastroenterol 2003; 40(4):209-215.

ABSTRACT - Background - An anatomic study about the arterial vascularization of the sigmoid was performed in order to obtain guidelines for the surgical treatment of rectal carcinoma. Aim - In the proposed technique, the sigmoid is brought down to the perineum, after radical anal-rectal resection, including sphincterectomy. Material and Methods - Thirty-three anatomical pieces were obtained through in situ dissection of formolized corpses ( 22 were male and 11 female). Turpentine solution, red marking, polyvinyl chloride were the materials used for preparation after cateterization of the inferior mesenteric artery. Results - The inferior mesenteric artery originated in most cases from the left side of the abdominal aorta, approximately $4.3 \mathrm{~cm}$ fromits bifurcation point; the left colonic artery, in 25 cases, originated straight from the inferior mesenteric artery below the left colonic artery, after which the sigmoid would be brought down to the perineum. Conclusion - Knowledge about arterial vascularization of the sigmoid could be helpful in the surgical management of rectal cancer.

HEADINGS - Sigmoid, anatomy \& histology. Mesenteric artery, inferior. Colostomy.

\section{REFERÊNCIAS BIBLIOGRÁFICAS}

1. Corsy F, Aubert. Artères de l'intestin grele et des colons. Bibliographie Anatomique 1913;2:221

2. Cunéo B. Sur un détail de technique dans l'extirpation abdomino-périnéale du rectum. J Chir (Paris) 1914;12:281-6.

3. Degni M. Estudo anátomo-cirúrgico das artérias do colo sigmóide e do segmento reto-sigmóide [tese]. Porto Alegre: Faculdade de Medicina da Universidade de Porto Alegre; 1947.

4. Drummond H. The arterial supply of the rectum and pelvic colon. Br J Surg $1913 ; 1: 677-85$

5. Esper FE. Contribuição ao estudo anatômico das artérias cólicas (arteriae colicae) e da irrigação das flexuras cólicas direita e esquerda (flexurae colicae dextra et sinistra) [dissertação]. Belo Horizonte: Faculdade de Medicina da Universidade Federal de Minas Gerais; 1983.

6. Gardner E, Gray DJ, O'Rahilly R. Esôfago, estômago e intestinos. In: Gardner E, editor. Anatomia - estudo regional do corpo humano. 4a ed. Rio de Janeiro: Guanabara-Koogan; 1978. p.368-83

7. Goligher JC. Adequacy of marginal blood-supply to the left colon after high ligation of inferior mesenteric artery during excision of rectum. Br J Surg $1953 ; 41: 351-3$

8. Griffiths JD. Surgical anatomy of the blood supply of the distal colon. Ann R Coll Surg Engl 1956;19:241-56.

9. Habr-Gama A. Indicações e resultados da retocolectomia abdominoendoanal no tratamento do câncer do reto [tese]. São Paulo: Faculdade de Medicina da Universidade de São Paulo; 1972.

10. Hollinshed WH, Rosse C. Intestino e seus derivados. In: Hollinshed WH, Rosse C. Anatomia. 4 ed. Rio de Janeiro: Interlivros; 1991. p.529-75.

11. Hovelacque A. Les artères mésentériques. Paris: Gaston Doin; 1933.

12. Jamieson JK, Dobson JF. The lymphatics of the colon. Ann Surg 1909;50:1077-90.

13. Kornblith PL, Boley SJ, Whitehouse BS. Anatomia da circulação esplâncnica. Clin Cir Am Norte 1992;1:1-29.
14. Lázaro-da-Silva A. Amputação abdominoperineal com colostomia perineal. Rev Bras Coloproctol 1991;11:105-8.

15. Lázaro-da-Silva A. Amputação abdômino-perineal mais colostomia perineal. In: Lázaro-da-Silva A. Tratamento do câncer reto-anal - colostomia perineal. São Paulo: Atheneu; 1998.

16. Michels NA, Siddharth P, Kornblith PL. Routes of collateral circulation of gastrointestinal tract as ascertained in a dissection of 500 bodies. Int Surg 1968;49:8-28.

17. Miles WE. A method of performing abdomino-perineal excision for carcinoma of the rectum and of the terminal portion of the pelvic colon. Lancet 1908;2:1812-3.

18. Moskowitz M, Zimmerman, Felson B. The meandering mesenteric artery of the colon. Am J Roentgenol Radium Ther Nucl Med 1964;92:1088-99.

19. Nahas P. Contribuição para o estudo da irrigação intraparietal do intestino grosso e suas implicações médico-hospitalares [tese]. São Paulo: Faculdade de Medicina da Universidade de São Paulo; 1970.

20. Riolan J apud Eycleshymer AC - Anatomical names. New York: William Wood; 1917.

21. Rosenblum JD, Boyle CM, Schwartz LB. Circulação mesentérica; anatomia e fisiologia. Clin Cir Am Norte 1997;2:295-311.

22. Schmidt E. The continent colostomy. World J Surg 1982;6:805-9.

23. Simonsen O. Câncer de reto. In: Corrêa Netto A, Raia AA, Zerbini EJ, editores. Clínica cirúrgica. 4ae ed. São Paulo: Sarvier; 1988. p.600-14.

24. Stewart JA, Rankin FW. Blood supply of the large intestine. Arch Surg $1933 ; 26: 843-91$

25. VanDamme JPJ. Anatomia comportamental das artérias abdominais. Clin Cir Am Norte 1993;4:745-71.

26. von Haller A. First lines of physiology. Troy - Obadiah Penniman; 1803.

27. Wainstein A. Irrigación arterial del intestino grueso. Arch Chilenos Morfol 1939;2:115-39

28. Wong SKC, Wee JTK. Reconstruction of an orthotopic functional anus after abdominoperineal resection. Aust NZ J Surg 1984;54:575-8.

Recebido em 22/1/2002. Aprovado em 14/4/2003. 